\title{
A SUPERLOTAÇÃO PRISIONAL NO BRASIL COMO ATAQUE AOS DIREITOS E GARANTIAS DA PESSOA HUMANA
}

\author{
PRISON OVERLOOTING IN BRAZIL AS AN ATTACK ON THE RIGHTS AND \\ GUARANTEES OF THE HUMAN PERSON
}

\author{
Abrelino de Castro Bitencourt ${ }^{1}$ \\ Alex Sandro Torbes Kessner ${ }^{2}$ \\ Dionatan dos Santos Duarte ${ }^{3}$ \\ Fabio Lopes Schwertz ${ }^{4}$ \\ Lucas Peixoto da Silveira ${ }^{5}$ \\ Carla Pilling dos Santos 6
}

\begin{abstract}
RESUMO: O presente artigo apresenta um estudo sobre a superlotação do Sistema Penitenciário Brasileiro, buscando demonstrar os imensos ataques a dignidade e aos direitos humanos, tanto das pessoas, quanto de seus familiares, funcionários do sistema e sociedade em geral. Com isso, através de exposição de dados objetiva-se provocar uma reflexão por parte do leitor quanto a real situação em que a os cidadãos estão enfrentando no cárcere. Como base de estudo para estre trabalho, utilizou-se da legislação com referência ao assunto, a exemplo da Constituição Federal de 1988 e Lei de Execução Penal do Brasil, bem como, pesquisas bibliográficas que abordam o tema, livros, publicações em artigos de revistas, sites e outros.
\end{abstract}

Palavras-chave: Superlotação, Sistema Prisional, Direitos e Garantias, Pessoa Humana.

\footnotetext{
I Graduado em Redes de Computadores pela Universidade Federal de Santa Maria, graduado em Segurança pública pela Uninter. Policial Penal pela Seapen/SUSEPE.

2 Graduando em Gestão Pública pela Universidade do Norte do Paraná - UNOPAR. Policial Penal pela Seapen/SUSEPE

3 Técnico em Contabilidade pela Escola Técnica de Canguçu- ETEC; Bacharel em Direito pela Faculdade Anhanguera Educacional; Tecnólogo em Administração de Empresas pela Universidade Norte do Paraná UNOPAR. Especialista em Direito Notarial e Registral pela Fundação Luiz Flávio Gomes - LFG; e Especialista em Gestão Prisional pela Faculdade Vila Nova do Imigrante - FAVENI. Policial Penal pela Seapen/SUSEP.

4 Graduado em licenciatura em História pela Ulbra São Jerônimo. Pós-graduado em Gestão Prisional pela Faveni. Policial Penal pela Seapen/Susepe.

5 Graduado em engenharia de produção pela Faculdade Anhanguera Educacional. Pós- graduado em Gestão prisional pela Faculdade Vila Nova do Imigrante - FAVENI. Policial Penal pela Seapen/Susepe.

${ }^{6}$ Graduada em Educação Física. Pós- graduada em Gestão prisional e inteligência policial pela FAVENI. E segurança pública e Gestão em serviços sociais e Políticas Públicas pela FAMART. Policial Penal pela Seapen/Susepe
} 
ABSTRACT: This article presents a study on the overcrowding of the Brazilian Penitentiary System, seeking to demonstrate the immense attacks on dignity and human rights, both of people, as well as their families, system employees and society in general. Thus, through the exposure of data, the aim is to provoke a reflection on the part of the reader as to the real situation in which the citizens are facing in prison. As a study base for this work, legislation with reference to the subject was used, such as the Federal Constitution of 1988 and the Law of Penal Execution of Brazil, as well as bibliographic research that addresses the topic, publications in magazine articles, websites and others.

Keywords: Overcrowding, Prison System, Rights and Guarantees, Human Person.

\section{INTRODUÇÃO}

A humanidade desde de os primórdios luta para melhorar a vida em sociedade, principalmente baseando-se em valores morais e culturais. Nesse caminho criou regras de convívio, subdividindo-se em grupos, dos quais os qualificados como cidadãos e o outro seria o grupo dos considerados um risco para a sociedade ou que preferem estar afastados da regra e descumprir as leis.

Contudo, mesmo com todo esforço, a sociedade vem sofrendo dia a dia com o avanço da criminalidade, e atualmente em destaque está o enorme e desenfreado aumento de presos no sistema prisional, o que leva as pessoas a sofrerem com ondas de insegurança e medo, pois este tipo situação afeta a todos.

Há muito tempo a história vem nos mostrando que no mundo, o sistema prisional está falido e não consegue alcançar os preceitos mínimos de dignidade para o cumprimento de pena. No Brasil isto não é diferente, a superlotação no cárcere constituindo uma violação dos direitos e garantias constitucionais, além de caracterizar uma violação direta dos direitos humanos. Desta forma, surge este trabalho com intuito de provocar uma reflexão através da visualização dos dados e também propor possíveis soluções para amenizar esse problema e, para isso, se faz necessário uma exposição, mesmo que sucinta do que ocasiona essa superlotação do sistema.

É sabido que o problema da superlotação não afeta somente o preso, mas sim a sociedade de forma geral, pois as pessoas privadas de liberdade não deixam de ser 
cidadãos por estarem no cárcere. As mazelas nas prisões são as mais variadas, desde sanitárias quanto em relação à segurança. As pessoas com restrição de liberdade que deveriam perder somente o seu direito de mobilidade, perdem também sua dignidade, e isso por não terem nem o menor atendimento adequado em um sistema que está extremamente lotado.

A legislação prevê direitos e deveres para os apenados, assunto tratado mais a frente, mas normas estas que infelizmente permanecem mais no papel do que na prática.

O Estado, este que deveria ser um membro atuante dentro dos presídios se torna um mero coadjuvante no sistema por não ter controle algum, e essa problemática abre espaço para a ação das facções no sistema, gerando um aumento na criminalidade, ao passo que o recrutamento de pessoas presas é uma constante prática pelo crime organizado.

Quanto a falta de dignidade ao qual a pessoa presa é exposta e a omissão do estado nas penitenciarias, ocasionam uma dificuldade maior para a ressocialização da pessoa presa e motivam uma maior reincidência em crimes.

Medias urgentes se fazem necessárias, como o real cumprimento da norma constitucional e demais legislações. A separação de presos conforme a infração é uma delas, a utilização efetiva das penas alternativas, ou mesmo atualização da legislação penal, com base no avanço da tecnologia. Também como ferramentas importantes, há o trabalho e o estudo nos presídios, iniciativas que deveriam ser tomadas com maior vigor pelo Estado para amenizar a reincidência e a superlotação.

\section{PRISÃO NO BRASIL - BREVE HISTÓRICO}

Assim como no restante dos outros países, o sistema prisional no Brasil sempre foi eivado de descaso para com o ser humano.

O início da história apresenta que a pena havia sido criada para apenas a pessoa 
aguardar sua punição, mas, com a evolução da sociedade passou a ser o próprio castigo em si.

Nesse sentido que cabe trazer aqui, exposição de (Beccaria, 1999), a justiça humana tende a sofrer modificações, dependendo da força política preponderante a época e espaço, quando assim asseverava:

"A justiça divina e a justiça natural são, por sua essência, constantes e invariáveis, porque as relações existentes entre dois objetos da mesma natureza não podem mudar nunca. Mas, a justiça humana, ou, se quiser, a justiça política, não sendo mais do que uma relação estabelecida entre uma ação e o estado variável da sociedade, também pode variar, à medida que essa ação se torne vantajosa ou necessária ao estado social. Só se pode determinar bem a natureza dessa justiça examinando com atenção as relações complicadas das inconstantes combinações que governam os homens.”

Importe destacar que política penitenciária não possuía espaço nas discussões das autoridades visto serem entendidas apenas como parte de domínio do poder. As políticas punitivas do Brasil baseavam-se em ordenações Manuelinas e Filipinas, as quais alicerçavamse apenas em um ideal, qual seja: intimação pelo terror, um aparelhamento de punição ante crime empregando-se ideias religiosas e políticas da época.

Conforme apresentado por (Magnabosco, 1998), foi apenas em 1929 que efetivamente tais políticas se efetivaram, e com a chamada Comissão Penitenciária Internacional, que se transformou na Comissão Penal e Penitenciária, originando Regras Mínimas da ONU, e depois da II Guerra Mundial, que fizeram surgir em vários países Leis de Execução Penal (LEP), a exemplo da Polônia, da Argentina, França, Espanha, Brasil, e outros estadosmembros da ONU.

Dados mostram que antes disso, em 1824 se estabelecia constitucionalmente regras de que as prisões além de seguras, também deveriam ser limpas e ventiladas, separando-se cada preso de acordo com a classificação de seus crimes, mas nada disso se exerce até hoje.

O texto Constitucional da época já previa a preservação e garanta de direitos básicos 
aos presos como norteia trecho do art. I79, da Carta:

[...] A inviolabilidade dos Direitos Civis, e Politicos dos Cidadãos Brazileiros, que tem por base a liberdade, a segurança individual, e a propriedade, é garantida pela Constituição do Imperio, pela maneira seguinte. [...] VIII. Ninguem poderá ser preso sem culpa formada, excepto nos casos declarados na Lei; [...]; XIX. Desde já ficam abolidos os açoites, a tortura, a marca de ferro quente, e todas as mais penas crueis. XX. Nenhuma pena passará da pessoa do delinquente. Por tanto não haverá em caso algum confiscação de bens, nem a infamia do Réo se transmittirá aos parentes em qualquer gráo, que seja. XXI. As Cadêas serão seguras, limpas, e bem arejadas, havendo diversas casas para separação dos Réos, conforme suas circunstancias, e natureza dos seus crimes. (CF/1824, art. I79, VII, XIX, XX e $\mathrm{XXI}$ )

A sociedade avançando e movimentos reformistas tomando força cada vez mais, tornou-se também imperiosa uma maior atenção para as questões do descaso ao sistema de penalização. Encabeçado no Rio de Janeiro pelo Instituto da Ordem dos Advogados, reforma penal se fazia sentir urgente no Congresso e apenas dois anos depois, as discussões tomaram força na Câmara e Senado Federal discutindo-se as bases de um projeto, mas como já era de se esperar, esbarrou na burocracia.

Regia o país, naquela época, o pensamento de Estado Novo, e em 1940, durante o governo de Getulio Vargas, é publicada a consolidação das Leis penais, completado com Lei modificadoras, chamado de Código Penal Brasileiro.

Deste momento em diante, as penas são divididas em principais e acessórias, dependendo da gravidade do delito, sendo de três tipos: reclusão, detenção e multa. Enquanto que as segundas consistem: na perda da função pública, nas interdições de direitos e na publicação da sentença. A reclusão é a mais rigorosa, executando-se de acordo com o sistema progressivo, dividindo-se sua duração em quatro períodos (PEREIRA CUANO 2010).

Esse modelo penal de 1940 veio a sofrer modificações bem mais tarde já nos anos de 1969, depois em 1977, I981 e 1984, sempre adequados aos interesses políticos e ideologia que imperavam à época. 
Embora todos os entraves enfrentados para a criação de uma política eficiente no sistema prisional, observa-se que já vem de muito tempo a preocupação dos legisladores para com a preservação dos direitos básicos dos reclusos, porém, a lei está longe de ser cumprida. Atualmente a lei brasileira prevê proteção ao ser humano contra-ataques a seus direitos, mas o que ocorre em nosso país no interior das penitenciárias é o verdadeiro terror. Cabe aqui, trazer o alerta de CASTRO SILVA (2012, p.oi):

É necessário haver uma mudança, nesse quadro lastimável existente em nossos presídios, todos somos dignos de vivermos como seres humanos, desta maneira, dar o respeito merecido a essas pessoas as quais se encontram isoladas da sociedade e o mínimo que um ser humano pode fazer, pois, por mais que o crime cometido seja barbárie, essa pessoa ainda é um ser humano é enquanto essa condição ela precisa ser tratada como tal.

A verdade sobre tudo isso e como bem expões o autor, o governo deve deixar de ser omisso diante do caos no cárcere, parar de usar medidas apenas paliativas e solucionar definitivamente os problemas que a história carcerária sempre apresentou.

\section{PRIVAÇÃO DA LIBERDADE E LEGISLAÇÃO PERTINENTE}

Se considerarmos a edição de leis e normas como parâmetro de preocupação pa com as questões de proteção do ser humano no cárcere, o Brasil estaria muito bem avaliado, pois caracteriza-se como um grande ratificador de diversos tratados nesse sentido.

A exemplo disso, cita-se a Declaração Universal dos Direitos Humanos, datada de dezembro de 1948, a qual serviu de base para diversos ordenamentos jurídicos e também para a constituição de 1988 no país. E em se tratando de regras internacionais, cita-se também as Regras Mínimas para tratamento de reclusos ${ }^{7}$, que foi instituída no I Congresso das Nações Unidas para Prevenção do Crime e para o Tratamento de Delinqüentes (1955, Genébra -

7 Regras adotadas pelo Io Congresso das Nações Unidas sobre Prevenção do Crime e Tratamento de Delinquentes, realizado em Genebra, em 1955, e aprovadas pelo Conselho Econômico e Social da ONU através da sua resolução 663 C I (XXIV), de 3i de julho de 1957, aditada pela resolução 2076 (LXII) de 13 de maio de 1977. Em 25 de maio de 1984, através da resolução 1984/47, o Conselho Econômico e Social aprovou treze procedimentos para a aplicação efetiva das Regras Mínimas. 
Suíça), bem como, a Convenção Americana sobre Direitos Humanos, também chamada de Pacto de San José da Costa Rica, aprovada na Conferência Especializada Interamericana sobre Direitos Humanos em novembro de 1969.

Estas normas que foram ratificadas pelo Brasil, de forma geral, objetivam estabelecer padrões e conceitos essenciais atualizados, com princípios e regras de organização penitenciária e boas práticas relativas ao tratamento de presos, tanto que o artigo il o Pacto assegura a proteção da honra e da dignidade, afirmando que: "toda pessoa tem direito ao respeito de sua honra e ao reconhecimento de sua dignidade" e ainda que "toda pessoa tem direito à proteção da lei contra ingerências ou ofensas”.

A lei maior de um país é sua constituição, e a Brasileira foi reeditada em I988, trazendo inúmeras proteções e garantia aos cidadãos, independentemente de sua condição de em liberdade ou não e, nesse sentido expressa em seu artigo 5o, inciso III, que: "ninguém será submetido a tortura nem a tratamento desumano ou degradante".

No mesmo norte, a Carta também impõe que deve ser mantido aos apenados:

a) direito à vida (art. $5^{\circ}$, caput da $\mathrm{CF}$ );b) direito à integridade física e moral (art. 5o, V, X e XLIV da CF); c) direito à liberdade de consciência e de conviçcão religiosa(art. $5^{\circ}$, VI, VII, VIII da CF) d) direito de representação e de petição aos Poderes Públicos, em defesa de direitos e contra abusos de autoridade (art. $5^{\circ}$ XXXIV, a, da CF); e) direito à expedição de certidões requeridas às repartições administrativas, para defesa de direitos e esclarecimentos de situações de interesse pessoal (art. 5으, XXXIV, "b", LXXII, "a" e "b" da CF); f) direito à assistência judiciária gratuita (art. 5으, LXXIV da CF) g) presunção de inocência nos incidentes de execução (art. 5으, LVII da CF); h) direito a indenização por danos morais em face de erro judiciário ou por prisão além do tempo fixado na sentença (art. $\left.5^{\circ}, \mathrm{LXXV}\right)$.

Bem refere, (COSTA, 2004) quanto a proteção do ser humano pela constituição, em sua obra sobre a dignidade da pessoa diante das sanções penais, que:

[...] no atual Diploma Constitucional, pensamos que o principal direito fundamental constitucionalmente garantido é o da dignidade 
da pessoa humana. É ela, a dignidade, o primeiro fundamento de todo o sistema constitucional posto e o último arcabouço da guarida dos direitos individuais. É a dignidade que dá a direção, o comando a ser considerado primeiramente pelo intérprete.

Outra importantíssima referência normativa em vigor, que também trata das regras para tratamento dos presos, além do cumprimento da pena, as condições de privação da liberdade, do trabalho e da remição da pena, é a Lei no 7.210/84 (LEP - Lei de Execuções Penais). Editada antes da CF/88, foi ratificada em seus preceitos mantendo-se a preocupação com o caráter humanitário do cumprimento da pena.

A LEP, como é citada, em seu artigo $3^{\text {o }}$ estabelece que ao condenado e ao internado serão assegurados todos os direitos não atingidos pela sentença ou pela lei, e em seu capítulo II, elenca o rol de assistências asseguradas aos presos:

\section{Da Assistência}

Art. io. A assistência ao preso e ao internado é dever do Estado, objetivando prevenir o crime e orientar o retorno à convivência em sociedade.

Parágrafo único. A assistência estende-se ao egresso.

Art. II. A assistência será:

I - Material;

II - À saúde;

III -jurídica;

IV - Educacional;

V-Social;

VI - Religiosa.

Outros direitos também são garantidos pela lei: art. 4I, XI, a) direito ao uso do próprio nome; b) direito à alimentação, vestuário e alojamento; c) direito a assistência médicoodontológica, sendo assegurado o direito de contratar médico de sua confiança pessoal; d) direito ao trabalho remunerado; e) direito de se comunicar reservadamente com seu advogado; f) direito a previdência social (auxílio- reclusão); g) direito a seguro contra acidente de trabalho; 
Da mesma forma o artigo trás: h) direito à proteção contra qualquer forma de sensacionalismo; i) direito à igualdade de tratamento, salvo quanto a individualização da pena; j) direito à proporcionalidade na distribuição do tempo para o trabalho, o descanso e a recreação; 1) direito à visita do cônjuge, da companheira, de parentes e amigos em dias determinados; $\mathrm{m}$ ) direito a contato com o mundo exterior por meio de leituras e outros meios de comunicação que não comprometam a moral e os bons costumes.

Percebe-se desta forma, que normas existem e bem estruturadas prevendo assistência ao preso, porém o estado não possibilita tal atendimento, omitindo-se e possibilitando a entrada do crime organizado para prestar essas assistências aos presos, tornando-os reféns do sistema.

O crime organizado sempre existiu no Brasil, porém começou a atuar como facção através dessas brechas deixadas pelo estado por não estar presente nas penitenciarias e facilitando o recrutamento de mão de obra. Onde o Estado não se faz presente um poder paralelo é criado para suprir essa falta.

\section{EDUCAÇÃO E TRABALHO COMO RESGATE DA DIGNIDADE}

A educação trata-se de um direito de todos os seres humanos sendo a pessoa presa ou não, o fato de um indivíduo estar preso não pode ser motivo para que a pessoa seja privada de seu direito a educação ou qualquer um dos outros direitos previstos pela Constituição Federal de 1988. Assim está expresso em seus artigos 205 e 206 referente ao tema:

Art. 205. A educação, direito de todos e dever do Estado e da família, será promovida e incentivada com a colaboração da sociedade, visando ao pleno desenvolvimento da pessoa, seu preparo para o exercício da cidadania e sua qualificação para o trabalho.

Art. 206. O ensino será ministrado com base nos seguintes princípios:

I - igualdade de condições para o acesso e permanência na escola;

II - liberdade de aprender, ensinar, pesquisar e divulgar o pensamento, a arte e o saber; 
A assistência educacional da mesma forma é prevista na Lei de Execução Penal, devendo ser disponibilizada a todos os reclusos conforme segue:

Art. 17. A assistência educacional compreenderá a instrução escolar e a formação profissional do preso e do internado.

Art. I8. O ensino de $\mathrm{I}^{\circ}$ grau será obrigatório, integrando-se no sistema escolar da Unidade Federativa.

Art. ı8-A. O ensino médio, regular ou supletivo, com formação geral ou educação profissional de nível médio, será implantado nos presídios, em obediência ao preceito constitucional de sua universalização. (Incluído pela Lei no 13.163, de 2015)

§ Io $\mathrm{O}$ ensino ministrado aos presos e presas integrar-se-á ao sistema estadual e municipal de ensino e será mantido, administrativa e financeiramente, com o apoio da União, não só com os recursos destinados à educação, mas pelo sistema estadual de justiça ou administração penitenciária. (Incluído pela Lei $\mathrm{n}$ - 13.163, de 2015)

§ 20 Os sistemas de ensino oferecerão aos presos e às presas cursos supletivos de educação de jovens e adultos. (Incluído pela Lei no 13.163 , de 2015)

§ 30 A União, os Estados, os Municípios e o Distrito Federal incluirão em seus programas de educação à distância e de utilização de novas tecnologias de ensino, o atendimento aos presos e às presas. 7.627 (Incluído pela Lei n- 13.163, de 2015)

Art. 19. O ensino profissional será ministrado em nível de iniciação ou de aperfeiçoamento técnico.

Parágrafo único. A mulher condenada terá ensino profissional adequado à sua condição.

Art. 20. As atividades educacionais podem ser objeto de convênio com entidades públicas ou particulares, que instalem escolas ou ofereçam cursos especializados.

Art. 2I. Em atendimento às condições locais, dotar-se-á cada estabelecimento de uma biblioteca, para uso de todas as categorias de reclusos, provida de livros instrutivos, recreativos e didáticos.

Art. 21-A. O censo penitenciário deverá apurar: (Incluído pela Lei no 13.163, de 2015)

I - o nível de escolaridade dos presos e das presas; (Incluído pela Lei no 13.163 , de 2015)

II - a existência de cursos nos níveis fundamental e médio e o número de presos e presas atendidos; (Incluído pela Lei n⿳0 13.163, de 2015)

III - a implementação de cursos profissionais em nível de iniciação ou aperfeiçoamento técnico e o número de presos e presas atendidos; (Incluído pela Lei no ${ }^{\circ}$.163, de 2015)

IV - a existência de bibliotecas e as condições de seu acervo; (Incluído pela Lei no ${ }^{\circ}$.163, de 2015) 
$\mathrm{V}$ - outros dados relevantes para o aprimoramento educacional de presos e presas. (Incluído pela Lei no 13.163 , de 2015)

Estudos mostram que dos mais de 700 mil presos do sistema penal brasileiro, menos de I3\% tem acesso à educação no sistema, 8\% são analfabetos e aproximadamente $70 \%$ não concluíram o ensino médio, o índice de reincidência no brasil gira perto de $70 \%$, mostrando que falta atuação do estado dentro do sistema prisional. Isto mostra tanto a falta tanto oportunidade de educação quanto oportunidade de trabalho, dispositivos estes que além de servirem para remissão tem o principal objetivo que é motivar ou preparar a pessoa presa para o que vem depois do cárcere, a sua vida fora do cárcere.

Outro método muito útil e com resultados positivos comprovados são as $\mathrm{APACs}^{8}$, que são programas de parceria com empresas, propiciando oportunidade de novos conhecimentos ao apenados, preparando-os para a vida em sociedade. Essa alternativa envolve dispensa uma maior atenção ao presidiário, principalmente ao egresso do sistema, unindo forças da família, do Estado, da comunidade e do próprio recluso, que passa a trilhar novos caminhos ao conquistar a liberdade.

Mesmo com todos estes mecanismos advindos da legislação vigente, o Estado continua apresentando níveis de resposta muito abaixo do mínimo, ocasionando um aumento muito expressivo no acumulo de pessoas presas e a criminalidade cada vez mais se expandindo.

Como se percebe, as atrocidades contra a dignidade da pessoa constantemente estão ocorrendo dentro dos estabelecimentos prisionais, descontroladamente sem nem um controle do governo, ou mesmo este vem sendo cumplice do problema que se instala. Esse cerceamento de direitos básicos e ofensas à dignidade da pessoa humana precisam corrigidos e não podem passar imunes, caso contrário que seguirá pagando o preço será a sociedade.

\section{MAPA PRISIONAL BRASILEIRO - SUPERLOTAÇÃO}


O Brasil apresenta superlotação do sistema em aproximadamente 70\% acima da lotação máxima do sistema das 415 mil vagas que o sistema possui a ocupação está em 704 mil pessoas presas, o Brasil prende muito e não da assistência para essas pessoas.

Pessoas presas são largadas dentro de um sistema precário, totalmente sem assistência do Estado e são deixadas para fazer escola ou serem recrutadas pelo crime. Pessoas presas em celas construídas para abrigar 5 pessoas onde são largadas 20 para sobreviver para os níveis básicos de dignidade as pessoas privadas de liberdade no Brasil estão tendo seu direito severamente violado.

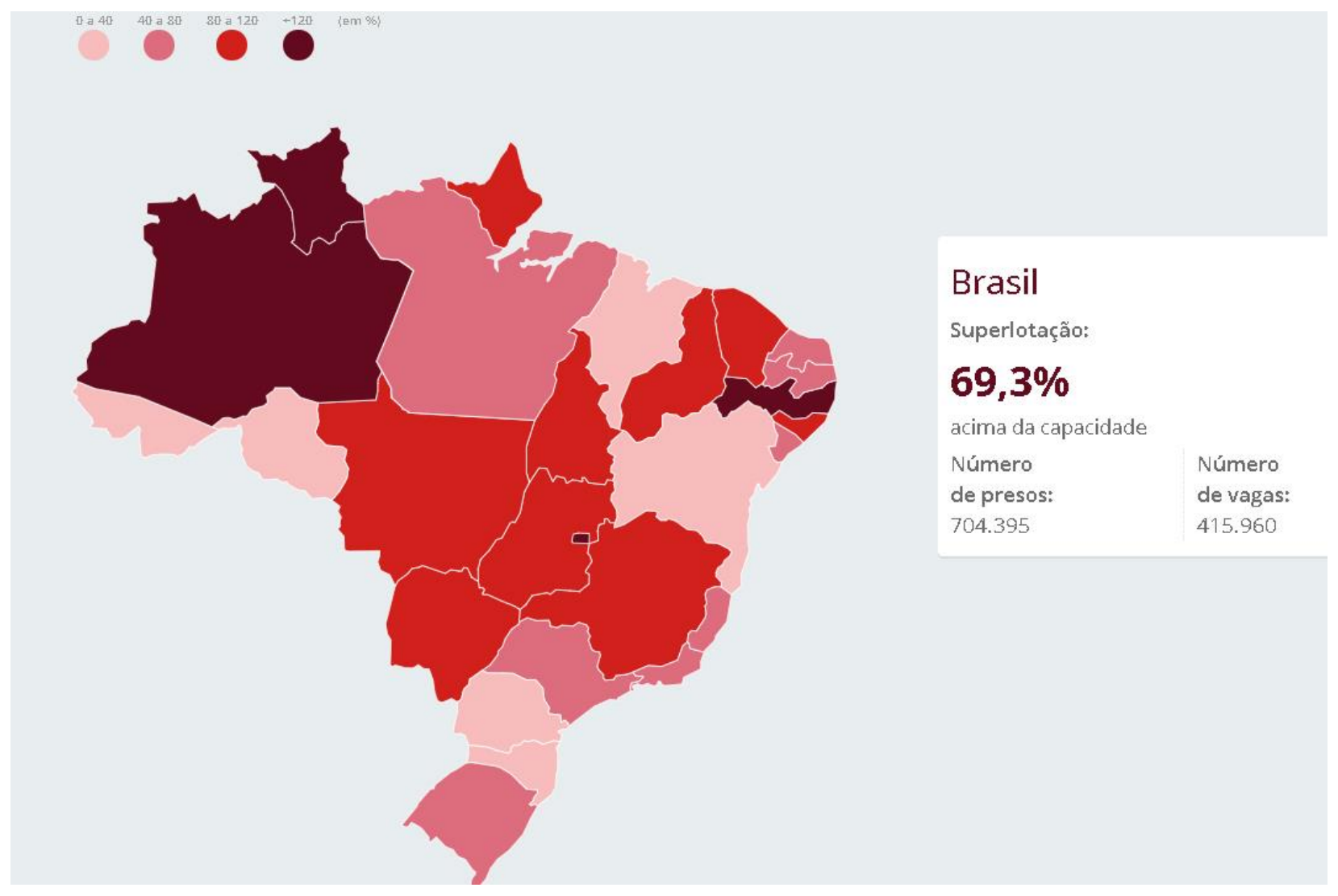

8 APAC: Um Modelo de Humanização do Sistema Penitenciário. Disponível em: https://ambitojuridico.com.br/cadernos/direito-penal/apac-um-modelo-de-humanizacao-do-sistema- 
Figurar: "Raio X do Sistema Prisional em $2019^{9}$

\section{I Sistema de separação de presos no cárcere}

No Brasil, além da Constituição Federal, a Lei de Execução Penal é quem prevê especificamente quanto a separação dos presos, assim conforme descrito abaixo:

Art. $84 \mathrm{O}$ preso provisório ficará separado do condenado por sentença transitada em julgado.

$\S^{\mathrm{I}^{\circ}}$ os presos provisórios ficarão separados de acordo com os seguintes critérios(Redação dada pela lei n⿳0 13.167, de 2015)

I - acusados pela pratica de crimes hediondos ou equiparados; (incluído pela Lei no 13.167 , de 2015)

II - acusados pela pratica de crimes cometidos com violência ou grave ameaça a pessoa; (incluído pela Lei no 13.167 , de 2015)

III - acusados pela pratica de outros crimes ou contravenções diversos dos apontados nos incisos I e II. (Incluído pela Lei nํํํ.1367, de 2015) (Lei № 7210 de II de julho i984)

Por falta de atuação do estado dentro das penitenciarias, a principal ferramenta utilizada pelo Estado para a separação dos presos dentro do sistema é a qual facção o detendo pertence superando as separações obrigatórias previstas em lei que seriam por crime, regime de prisão, condenados ou provisórios.

Nessa linha note-se o que diz (RIBEIRO, 2009).

O Estado deslocou seu foco, para uma simples manutenção da ordem, esquecendo-se dos princípios orientadores, seus fundamentos, isto leva a mudança de visão acerca do preso, pois quando o próprio Estado esquece que o individuo preso é um cidadão que faz parte do mesmo, isto se reflete em toda sociedade, a qual passa a tratar o preso, mesmo depois de ter cumprido apena, como não mais sendo este um cidadão.

Essa inatividade do estado acaba possibilitando o fortalecimento do crime organizado dentro dos presídios, e por não ter espaço para presos primários estes são colocados dentro de

penitenciario/acesso em: fev 2I. 
galerias dominada pelo crime, estes restando posteriormente recrutados e evoluindo para crimes mais graves ou piores dos que ocasionaram a sua prisão.

Este critério de separação não previsto em lei, atualmente é adotado pelas administrações dos estabelecimentos prisionais, vislumbrando-se e utilizando-se do argumento voltado às questões de segurança do apenado, mantendo-o em grupos aliados para que se preserve principalmente sua integridade física.

Sistema sucateado, falta de servidores, instalações que não comportam o número de reclusos, pessoas presas a todo instante, governo completamente desinteressado na solução do problema. Este é o verdadeiro retrato do sistema prisional brasileiro na atualidade.

\section{CONSIDERAÇÕES FINAIS}

Com este trabalho foi possível descrever, mesmo que de forma sucinta, um diagnóstico geral a respeito do Sistema Prisional do Brasil. Com os dados apresentados ao longo do trabalho e os estudos bibliográficos, demostrou-se a grave violação dos direitos e garantias fundamentais que o país impões as pessoas presas.

Facilmente o que se percebe, é que pouco avançou o Estado Brasileiro no que se refere a forma de cumprimento de pena, seja quanto ao número de pessoas presas, quanto as condições para que ocorresse.

Degradação da dignidade da pessoa humana é o que há de mais perceptível, além de um Estado que se esconde e/ou foge de suas obrigações. Governantes que apenas se usam de medidas paliativas e nada fazem para que se tenha uma real solução das mazelas penitenciárias.

9 Observação: Dados preservados, cores alteradas para melhor visualização. Disponível em: http://especiais.g1.globo.com/politica/2017/raio-x-do-sistema-prisional/acesso em: fev 21. 
Se faz necessário urgentemente que se perceba as pessoas presas como parte da sociedade, e assim oportunizar lhes ocupações que lhes trarão uma nova visão de vida, neste sentido, disponibilizando educação e trabalho, a fim de prepará-los para seu retorno de convivência em sociedade.

Enfim, o que fará com que essa decadência do sistema prisional venha a tornar-se em restauração da sociedade, será o engajamento de todos os segmentos jurídicos e sociais, na busca de efetivar os preceitos legais que norteiam o cumprimento da pena. Ou seja, apenas com a união de esforços no sentido de viabilizar a ressocialização do egresso é que a sociedade terá possibilidade de dignificar seu desenvolvimento.

\section{REFERÊNCIAS}

BRASIL. Lei n.o 7.210, de II de julho de 1984. Disponível em: <http://www.planalto.gov.br/ccivil_03/LEIS/L7210.htm.> Acesso em: I5 de fevereiro de 2021.

BRASIL. Constituição Federal de 1988. Disponível em: <http:// www.planalto.gov.br/ccivil_03/Constituicao/ConstituicaoCompilado.htm>. Acesso em: is fev 2I.

Conselho Nacional de Justiça. Disponível em: http://www.cnj.jus.br/ Acesso em: is fev 2I.

BECCARIA, Cesare. Dos delitos e das penas. I ed. São Paulo: Edipro, I999.

FREIRE, P. (1983). Educação e mudança. 7., Rio de Janeiro: Paz e Terra.

MAGNABOSCO, Danielle. Sistema penitenciário brasileiro: aspectos sociológicos. Jus Navigandi, Teresina, 1998. Disponível em: http://jus2.uol.com.br/doutrina/texto.asp?id=ıoro. Acesso em: 28 fev 2I.

PEREREIRA CUANO, Rodrigo. História do Direito penal Brasileiro. Disponível em: http://www.uj.com.br/publicacoes/doutrinas/884/historia_do_direito_penal_brasileiro. Acesso em: Io mar 21.

RaioX do Sistema Prisional Disponível em: https://especiais.gi.globo.com/monitor-da- 
violencia/2019/raio-x-do-sistema-prisional/ Acesso em is fev 21.

Regras Mínimas para o Tratamento dos Reclusos - 1955. Disponível em: http://www2.camara.leg.br/atividade-legislativa/comissoes/comissoespermanentes/cdhm/comite-brasileiro-de-direitos-humanos-e-politicaexterna/RegMinTratRec.html Acesso em: I8 mar 2I.

Relatório de reincidência criminal. Disponível em: https://www.ipea.gov.br/portal/images/stories/PDFs/relatoriopesquisa/I506II_relatorio_rei ncidencia_criminal.pdf Acesso em: 27 mar 21.

SILVA, Eduardo Araújo. Crime Organizado. São Paulo: Atlas, 2003.

SILVA, SILVA, Juliana Nunes Castro. A dignidade da pessoa humana a falta de dignidade dentro dos presídios brasileiros. Conteúdo Jurídico, Brasília-DF: I8 set. 2012. Disponível em: http://www.conteudojuridico.com.br/?artigos\&ver=2.39196\&seo=I Acesso em: 25 mar 2I. https://domalberto.edu.br/revista/revista-da-faculdade-dom-alberto-v-I2-n-2-2014/ 